\title{
The Impact of Beijing Smog and Control Actions
}

\author{
Wang $\mathrm{Di}^{1}$, Zhang $\mathrm{Bo}^{2}$ and Luo $\mathrm{Dan}^{3}$ \\ 1.Wang Di(1992 ),female, master's degree,research direction: ecological civilization,low-carbon \\ finance \\ 2.Zhang Bo (1972 ), male, associate professor, master tutor, research direction: enterprise low \\ carbon strategy \\ 3.Luo Dan (1991 ), female, master's degree, research direction: ecological civilization,low-carbon \\ finance

\section{3@qq.com, zhangbo@buu.edu.cn,1020279524@qq.com}

Keywords: Beijing; Haze; Influence; Governance

Abstract: In this paper, mainly through questionnaire's form, the citizens of Beijing to understand the degree of attention and cognitive haze of pollution control proposals, according to the degree of the pollution in Beijing City, with reference to foreign successful management experience, put forward relevant measures about haze pollution control. At the same time, to let more people know about the harm to the human body to haze, which cause height to take seriously, pay attention to the protection measures, and promote environmental protection and healthy life, the control of Beijing city environmental protection and propaganda haze play a positive role.

\section{Introduction}

This paper carries out an investigation on Beijing's smog phenomenon from knowing the basic knowledge of smog, making an overview and analysis of the current smog problem in Beijing, and analyzing the main causes of smog. The paper aims to understand the masses' understanding and awareness of the haze phenomenon, and the main harm to Beijing caused by smog using questionnaires. With reference to references and data of Beijing Municipal Environmental Monitoring Center, an in-depth study is carried out to study the influence of smog on Beijing and its harm to the human body. Combined with the results of the questionnaires, the paper puts forward the plan for prevention and control of smog in Beijing.

\section{Current situation of Beijing's smog and cause analysis}

\section{Current situation of Beijing's smog}

Beijing Municipal Environmental Protection Bureau announced that the average PM2.5 concentration in 2015 was $80.6 \mu \mathrm{g} / \mathrm{m}^{3}$, which was 1.3 times of the new national standard $35 \mu \mathrm{g} / \mathrm{m}^{3}$. The monitoring data result is shown in Fig. 1.1. 

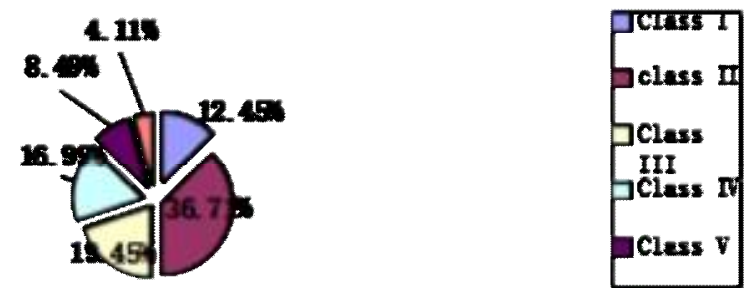

Fig. 1.1 Distribution of air quality level 2015

(Source: Beijing Municipal Environmental Protection Bureau, issued on Jan. 4, 2016)

In 2015, there were 52 days of class I air quality, accounting for $14.25 \%$; 134 days of class II air quality, accounting for $36.71 \%$; 71 days of class III mild pollution, accounting for $19.45 \%$ and so on. The conclusion is as follows:

I: Severe smog conditions occur once a week, as shown in Fig. 1.2

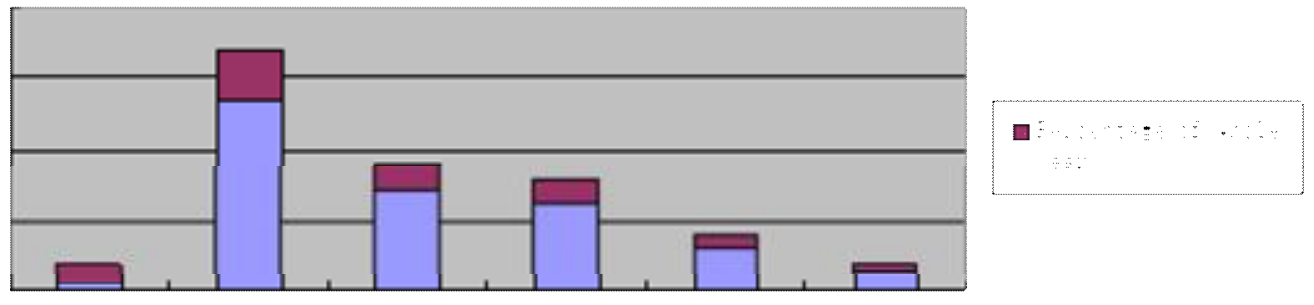

Fig. 1.2 The number of days of pollution in Beijing in 2015 and its percentage of the whole year

(Source: Beijing Municipal Environmental Protection Bureau, issued on Jan. 4, 2016)

II: The primary pollutant is PM2.5 $5^{[1]}$

Of 295 days that exceed the standard, PM2.5 accounted for 65\%; followed by ozone, accounting for $41 \%$; and other pollutants $\left(\mathrm{PM} 10, \mathrm{NO}_{2}\right)$ only accounted for $4 \%$, as shown in Fig. 1.3:
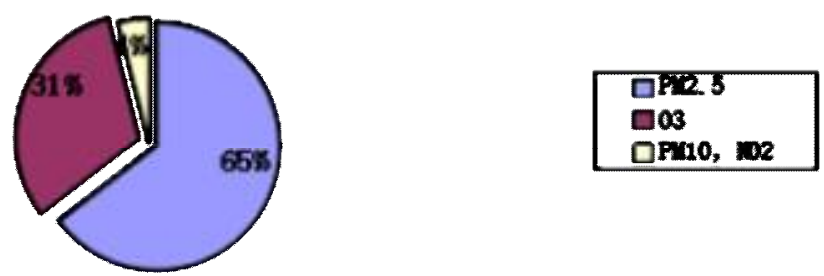

\section{Fig. 1.3 Proportion of air pollution in the days exceeding the standard}

(Source: Beijing Municipal Environmental Protection Bureau, issued on Jan. 4, 2016)

III: Monthly average PM2.5 concentration

Fig. 1.4 shows the monthly concentration of PM2.5 in 2015. As shown below in Fig. 1.4, the overproof phenomenon is the most serious in December. The monthly average PM2.5 concentrations after August showed a clear upward trend. 
Monthly average PM2.5 concentration in 2015

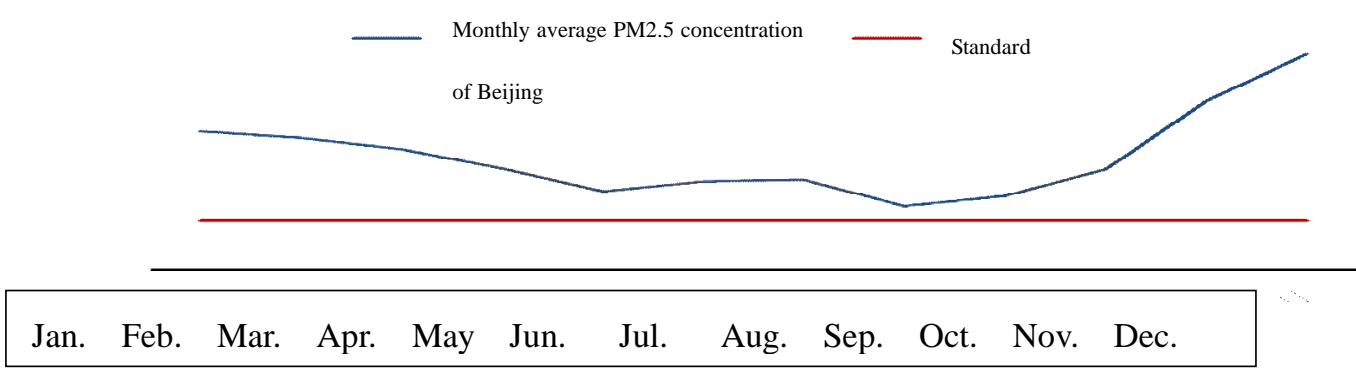

Fig. 1.4 Monthly average PM2.5 concentration in 2015

(Data from http://www.cnemc.cn/)

\section{Major sources of Beijing smog}

The records of the main components of air pollution in Beijing in 2015 and early 2016 made by Beijing Municipal Environmental Protection Bureau and the study of this paper showed that the zone transfer contributed to about 28-36\% of PM2.5 in Beijing, and local pollution discharge accounted for $64-72 \%$. Among the local pollution sources, motor vehicles, coal mine, industrial production and dust were major sources, accounting for $31.1 \%, 22.4 \%, 18.1 \%$ and $14.3 \%$ respectively, other emissions such as catering, motor repair and livestock breeding accounted for 14.1\% of PM2.5. See Fig. 1.5.

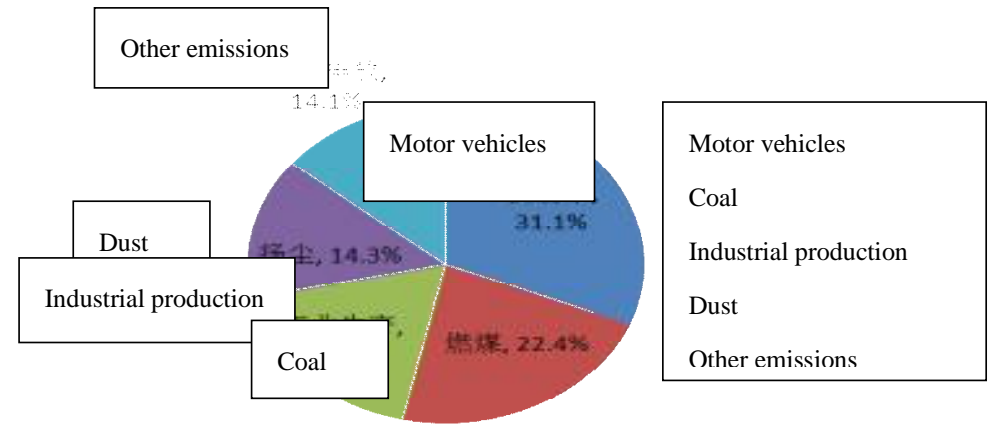

Fig. 1.5 Major sources of Beijing smog

(Source: Beijing Municipal Environmental Protection Bureau, issued on Apr. 16, 2014)

Data shows that the early development of motor vehicles is an important cause of haze, accounting for $31.1 \%$. Coal is one of the main sources of PM2.5 in Beijing, accounting for $22.4 \%$. Restricted by its own orographic influence and Beijing's own air purification capacity constraints, plus the continuous population growth, and the growing number of vehicles, these undoubtedly pose huge challenges for the prevention and control of atmospheric pollution.

\section{Analysis of impact and harm of air pollution in Beijing}

According to the survey of air quality by experts and scholars in recent years, hazy weather has affected the economic development of Beijing, caused some traffic jams, accelerated the spread of microorganisms and germs, and also caused certain impact on the aquaculture industry in Beijing. Besides, in recent years, tourism is not as good as previous years. All in all, smog has had a profound impact on Beijing's economy and people's health. 


\section{The influence of smog on Beijing's industrial economy \\ Effects of smog on Beijing transportation}

Firstly, for road traffic, the drivers' sight is blocked under the influence of suspended particles in the air in the hazy weather, which lead to a wrong judgement for the road condition, and thus likely to cause traffic accidents;

Secondly, for transportation, in areas that are severely affected by hazy weather, flight delays or even the phenomenon of flight cancellations occur, trains and highways are also affected to varying degrees.

\section{Effects of smog on Beijing tourism}

In the survey, many tourists indicated that poor visibility caused poor quality photos, thereby they reduced their outside activities, some tourists even preferred to take a trip in some southern cities with good air quality. From the data of scenic spots released by Beijing travelling website, during China's national day holiday between Oct. 1 and Oct. 7 in 2015, Beijing Badaling Great Wall, the Ming Tombs, the Forbidden City and other popular scenic spots are in the "high comfort" state, which the visitors flow rate of the Forbidden City is 12,100 passengers, far from its annual average daily number of tourists throughout the year, that is more than 40,000 .

\section{Effects of smog on aquaculture in Beijing suburb}

Farmers said that with the increase of hazy weather, livestock and poultry lost appetite, while the incidence of respiratory diseases significantly increased. The main reasons include: first, the pollutants are not easy to spread, plus the pollution gas indoor itself, air circulation in an outdoor area cannot be conducted, making the concentration of indoor pollution gas surge, and the immunity of livestock and poultry decreases with the declining air quality, causing harm to developmental health; after PM2.5 particles enter into the respiratory tract of animals, it accelerated bacterial reproduction, causing various diseases of animals ${ }^{[2]}$.

\section{Harmful effects of smog on people's physical and mental health \\ Diseases affecting cardiovascular system}

Long-term inhalation of PM2.5 can lead to arrhythmia, heart failure, cardiac arrest and other related cardiovascular diseases. Medical researchers found that per $10 \mu \mathrm{g} / \mathrm{m}^{3}$ rise in PM2.5 may increase the cardiovascular disease by $0.4 \%$ to $1.0 \%$.

\section{Resulting in respiratory diseases, or even lung cancer}

When PM2.5 is breathed into the lungs, it will lead to decline in function of bronchial system in the long run, and even lead to loss of ventilation function. Long-term inhalation of PM2.5 particulate matter may lead to reduction of respiratory defense function, and the occurrence of bronchial, asthma and other related respiratory diseases. The study found that per $10 \mu \mathrm{g} / \mathrm{m}^{3}$ rise in PM2.5 may increase the incidence of bronchitis by 29\%, and lung cancer is mainly affected by environmental factors, long-term respiration of contaminated air may cause lung cancer.

\section{Resulting in rickets}

Children's rickets are caused by two main factors, the lack of vitamin D, and a result of calcium deficiency. As hazy days are fog-shrouded, the sunshine is reduced, and the haze greatly reduces ultraviolet radiation, sunlight is an important channel to provide vitamin $\mathrm{D}$, resulting in insufficient sunlight exposure to children, and causing Vitamin-D deficiency rickets.

\section{Negative effects on mental health ${ }^{[3]}$}

From a psychological point of view, if a person lives without sunlight for a long time, he or she will feel dull and depressed, thereby intensifying the psychological state of depression. The sun is 
blocked and the light is weakened due to haze, resulting in lower air pressure, and people will feel absent-minded and upset.

\section{Suggestions on prevention and control of smog in Beijing}

\section{My suggestions on smog control}

Emission reduction $^{[4]}$

First, to prohibit all vehicles from driving in heavily polluted areas; second, to limit or close large-scale boilers and industrial equipment; third, to restrict the amount of dust in construction sites. In addition, special attention should be paid to avoid the burning of wood or garbage.

\section{Building a low-carbon ecological society}

First, the government should introduce policies to curb industrial pollution, improve public transport networks, and reduce traffic congestion; second, the air quality strategy should be developed, and air quality management areas must be lined out in non-compliance areas, and the standard must be reached within the prescribed time limit; third, sprinkle calcium-based adhesive on the street to control air pollution, which can absorb dust in the air, so that the particles of contaminated area have been significantly reduced.

\section{Establishing an air quality research center ${ }^{[5]}$}

First, use of clean energy for buses and light trucks, and multi-level emission standard monitoring has been implemented so that emissions were cut by more than $90 \%$; second, citizens can conduct real-time monitor on PM2.5m, participate in the public hearings held by environmental protection agencies, and give feedbacks at any time; third, people can download mobile applications to understand the PM2.5 and ozone monitoring data at any time in real time so as to conduct 24-hour air quality monitoring.

\section{Beijing Municipal Government's measures on air pollution control}

\section{Pollution control of motor vehicles}

1) Promoting green travel, and the construction of public bicycle service system

By drawing lessons from Shenzhen's "subway + bicycle" mode of travel, it shall increase the number of bicycle parking spots or strengthened the supervision of the bike shed, or encourages the bicycle rental industry at low prices to increase the usage rate of bicycles.

2) The use of new energy vehicles shall be encouraged. Liquefied natural gas, hybrid and other new energy replace gasoline to reduce vehicle exhaust emissions or put more electric buses in place.

3) Eliminating high-emitting old motor vehicles

Vehicles reaching retirement life shall be strictly supervised, the safety technology of vehicles shall be inspected, and unqualified vehicles shall be eliminated to reduce vehicle exhaust emissions.

4) Strengthening the pollution control of vehicles in use ${ }^{[6]}$

It shall continue to intensify efforts to carry out spot check the public transport, sanitation, postal service, rental, tourism, inter-provincial passenger transport, waste transport and other key industries and cargo vehicles and take serious measures to impose severe penalties of vehicles exceeding standard.

\section{Industrial pollution and dust control}

Heavy industrial enterprises shall be strictly supervised and a variety of exhaust emissions shall be strictly restricted, once the phenomenon of excessive emission is investigated, specific 
punitive measures should be taken (no penalty cap), and the emissions of $\mathrm{SO}_{2}$, nitrogen oxides and dust shall be monitored. The dust on construction site should be controlled, and construction enterprises should be constrained in strict accordance with the law. First, environmental protection education should be conducted for construction workers and the construction process should under strict supervision; second, the surrounding areas of construction sites should have barriers in order to prevent the outflow of harmful gases and dust fog; third, in the construction process, before transport vehicles, excavators and other equipment leaving the site, dust must be removed and no dust is allowed to take out of the site; finally, after the completion of the project, surrounding areas of construction sites must be cleaned up in time, including the removal of barriers ${ }^{[7]}$.

\section{Regulation of refuse combustion}

The dense smoke generated by the combustion of garbage causes the increase in the concentration of pollutants in the air. If the burning of plastic bags is accompanied by toxic smoke and dust, such smoke and dust can easily cause human respiratory diseases, and even lead to cancer. In order to prevent incineration of garbage, sanitation departments should strengthen supervision. The public should also cut down refuse burning behaviors, consciously maintain environmental health, and also should reduce the discharge of fireworks, especially during the Spring Festival.

\section{Control of coal and management of cooking fumes}

Under the circumstances that people's life cannot be separated from coal, natural gas can be used to replace coal, or new energy sources should be developed to replace coal. The emissions of fire coal should be strictly supervised, and relative measures shall be taken once it exceeds standard. Central heating shall be implemented in winter to reduce the combustion of coal.

For the oil-smoke pollution in catering industry, the use of natural gas, electricity and other clean energy should be encouraged; the supervision of business sites of catering industry shall be strengthened. Efficient fume purification facilities should be installed and barbecue outdoors shall be strictly prohibited.

\section{Government shall formulate relevant policies to be supervised by citizens}

From the experience of air pollution control in foreign countries, strengthening and perfecting the legislation, and implementation of environmental protection work is the key to solve environmental management problems. The government should pay attention to detailed rules and regulations, strengthen law enforcement supervision, and monitor environmental law enforcement through non-governmental organizations and public authorities. Reporting platforms shall be set up to give the public the right to monitor, monitoring facilities should be increased to enhance citizens' monitor of pollution.

Specific measures: first, improve monitoring standards through lawmaking to improve air quality; second, scientific planning of public transport to reduce vehicle congestion on the road; third, control exhaust emissions and reduce emissions of pollutants; fourth, construction of urban greenbelt in a scientific manner ${ }^{[8]}$.

\section{Environmental responsibility of the public}

1) Healthy eating habits and smoking less

Volunteers have done experiments to fry food under conditions of closing the window and kitchen ventilator, the maximum concentration of PM2.5 is 58 times of the standard instantly, besides, fried and barbecue food are easy to destroy the nutritional structure of food and lead to fatness. Therefore, whether it is responsible for our own health or from the environmental protection point of view, we should develop long-term healthy eating habits and reduce the 
consumption of barbecue food, thereby reducing environmental pollution while protecting our own health.

2) Traveling by public transport or by bike

Emissions from vehicle emissions are a significant contributor to PM 2.5. If we travel by bicycles or public transport, we will reduce private car use and thus reduce exhaust emissions.

\section{Conclusions}

For the causes of haze pollution in Beijing, the paper proposes relevant control measures to strengthen environmental protection legislation, and strengthen supervision at the same time, conduct strict control on vehicle emissions beyond standard and take related measures. Through the investigation of the haze control and the degree of concern, it is concluded that the public's concern about the haze is not enough. Most people are not aware of the long-term harm of smog, and the environmental awareness is not strong. The government news report should advertise the harm of smog to raise people's attention. The public generally believe that exhaust emissions is a big problem in Beijing, and strong measures should be taken to control traffic flow and reduce exhaust emissions. Citizens do not take appropriate protection measures in hazy weather, and some people even do not wear masks to go out on heavy pollution days. ${ }^{[9]} \mathrm{A}$ lot of people have not equipped with N95 masks, and have not attached great importance to personal hygiene after going out on hazy days.

Based on foreign experience, smog control is a long process, and in this process, the public should perform environmental protection duties by reducing private car use and choosing environmentally friendly travel mode. In the current situation of frequent occurrence of hazy weather, we should go out less, and wear N95 masks especially in heavily polluted weather and hazy days to reduce the harm of haze to the greatest extent.

\section{Acknowledgements}

This work was financially supported by the talent strong school plan of Beijing Union University talented person projects "Enterprise Voluntary Implementation of the Construction of Ecological Civilization Theory and Practice Research" (project number Rk100201504) and 2013 national social fund project "The Enterprise Desire and Behavior of the Implementation of the Construction of Ecological Civilization Studies" (item number 13 bg1073) funding.

\section{References}

[1] < CPC Central Committee on the development of the national economy and social development of the five thirteenth year plan proposal >

[2]Matthew S Landis, Gary A Norris, Ronald W Williams,Jason P Weinstein. Personal exposures to PM 2.5 mass and trace elements in Baltimore, MD, USA[J]. Atmospheric Environment,2001,3536:.

[3]Aniket A. Sawant,Kwangsam Na,Xiaona Zhu,David R. Cocker. Chemical characterization of outdoor PM 2.5 and gas-phase compounds in Mira Loma, California[J]. Atmospheric Environment,2004,3833:.

[4]Zhang Xiaoye, Sun Junying, Wang Yaqiang, Li Weijun, Zhang Qiang, Wang Weigang, Cao Guoliang, Wang Jizhi, Jiannong right, Yang Yuanqin, Zhang Yangmei. Thinking about the cause and treatment of haze in China fog - [J]. Science Bulletin, 2013,13:1178-1187. 
[5]Hu Mingwei. Haze economic analysis [J]. Economic Research Journal, 2013,16:13-15.

[6]Meng Xiaoyan, Yu Yu, Zhang Zhifu, Li Gang, Wang Shuai, Tully. In January 2013, the cause of strong haze in Beijing, Tianjin region and the cause of the study [J]. environmental science and technology, 2014,01:190-194.

[7]Liu Xiaoyun, Xie Peng, Liu Zhaorong, Li Tiantian, Zhong Ju Ju, Rong Rong. The economic loss assessment of the acute health effects of particulate matter pollution in the Pearl River Delta [J]. Journal of Peking University (NATURAL SCIENCE EDITION), 2010,05:829-834.

[8]Zhang Shiqiu. Haze governance need to build a system of strategic and long-term mechanism [J]. green leaves, 2013,11:19-25.

[9]Jia Kang: governance haze with economic leverage [N]. China Electric Power News, 2015-03-09002. 